\title{
General Psychiatry China says no towards the second large- scale COVID-19 outbreak: voices from the online public
}

Xiaona Zhou, Junlan Liu, Wei Wang, Chunlei Jiang

To cite: Zhou X, Liu J, Wang W, et al. China says no towards the second large-scale COVID-19 outbreak: voices from the online public. General Psychiatry 2021;34:e100517. doi:10.1136/ gpsych-2021-100517

- Additional supplemental material is published online only. To view, please visit the journal online (http://dx.doi.org/10.1136/ gpsych-2021-100517).

Received 27 February 2021 Accepted 27 September 2021

Check for updates

(C) Author(s) (or their employer(s)) 2021. Re-use permitted under CC BY-NC. No commercial re-use. See rights and permissions. Published by BMJ.

Department of Stress Medicine, Faculty of Psychology, Second Military Medical University, Shanghai, China

Correspondence to Professor Chunlei Jiang; cljiang@vip.163.com
With its fast and wide spread, coronavirus disease 2019 (COVID-19) caused by a novel coronavirus broke out suddenly in Wuhan, China at the end of 2019. It posed a grave threat to human life and health, and brought massive challenges to global health. On 30 January 2020, the World Health Organization (WHO) declared the novel coronavirus constituted a 'public health emergency of international concern'. ${ }^{1}$ Due to its rapid transmission, it drew attention from more than 200 countries and areas worldwide. To prevent its spread, the WHO declared the novel coronavirus outbreak was a global pandemic on 11 March 2020. Meanwhile, it called for a global effort to combat the disease. ${ }^{2}$ China was the first country hit hardest by the disease. Facing this unknown, unexpected and devastating disease, the Chinese government rapidly took decisive and strong measures, for instance, complete lockdown, strict movement control on residents and closing public spaces. ${ }^{3}$ The epidemic in China was effectively controlled by the end of April 2020 with the support and assistance provided by the international community. Since then, China's epidemic prevention and control has entered normalisation. But the battle against the epidemic is still ongoing in China.

Currently, a year has passed since the first cluster of COVID-19 cases was reported. ${ }^{4}$ The coronavirus is raging all over the world and has affected more than 200 countries and territories, which resulted in widespread medical complications and loss of life, and impacted global economies and people's daily lives ${ }^{5}$. For example, the pandemic has impeded the flow of people, cross-border trade and other economic activities, triggered fluctuations in financial markets, and delivered a blow to both global industry and supply chains.

More than 210 million people were infected during the pandemic, of whom over 4.5 million people lost their lives as of
30 August 2021. Strict control and quarantine measures have been taken around the world and the rate of new confirmed cases has declined, but the situation has not been effectively controlled-the global cumulative confirmed cases continue to increase. Due to the high infectivity and continuous variability of the virus, the large number of asymptomatic carriers and the lack of effective antiviral drugs, the prevention and control of COVID-19 is still extremely difficult. ${ }^{6}$

In the past several months, sporadic cases have been reported on the mainland, resulting in case clusters in some locations (eg, Xinjiang, Beijing, Qingdao, Hebei, Jilin and Shanghai). It was reported that many cases were from outside travellers coming into the country, imported cold-chain food was frequently tested positive for COVID-19 nucleic acid and asymptomatic carrier also appeared occasionally. As we all know, China is a country with a large, highly mobile population, which makes prevention and control of COVID-19 quite challenging.

With full consideration of the current status of the pandemic, both domestically and abroad, we wonder if there will be a second large-scale outbreak in China. How does the Chinese public perceive this issue? How much confidence does the Chinese public have in the government and their own ability to cope with a possible second outbreak? To answer these questions, we conducted an online survey. It has shown that understanding the knowledge, attitudes and behaviour of the general public regarding COVID-19 plays an integral role in the prevention and control of the pandemic. ${ }^{78}$ Therefore, it is essential to clarify the attitudes and behaviour of the public towards COVID-19.

Then, we conducted a cross-sectional online survey by sharing web links through WeChat Snowball, which linked to a questionnaire containing 24 questions (see online 


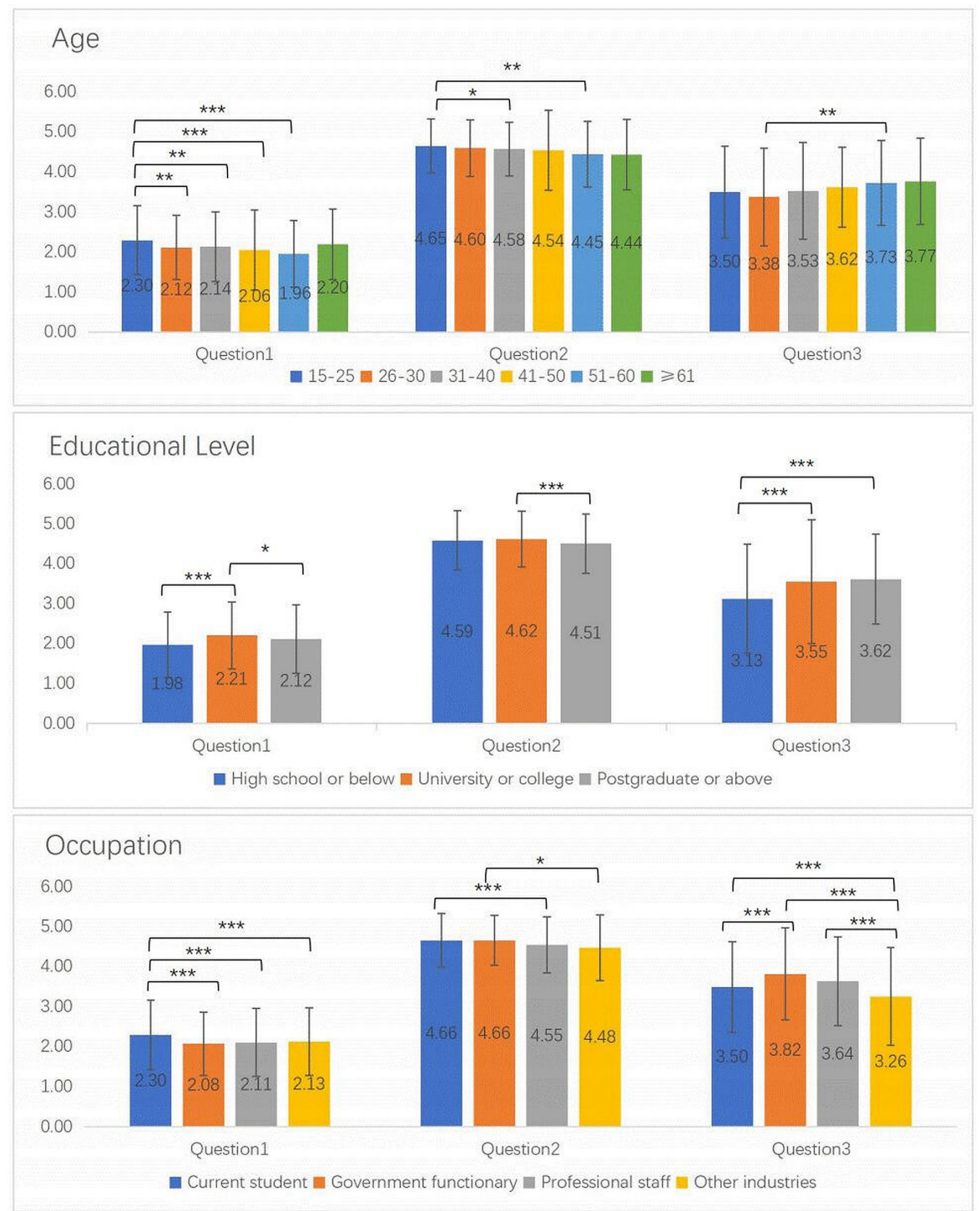

Figure 1 The comparison of the public's perceptions on three questions related to COVID-19 across age, educational level and occupation $(n=2399) .{ }^{*} p<0.05 ;{ }^{* *} p<0.01 ;{ }^{* *} p<0.001$. Question 1 : What do you think is the likelihood of a secondary largescale outbreak in China? Question 2: If COVID-19 secondarily breaks out, how much confidence do you have in government's ability to deal with the epidemic? Question 3: If COVID-19 secondarily breaks out, how much confidence do you have in your ability to deal with the economic, work and life stress caused by the outbreak?

supplemental file 1 for more details). Participants were invited to fill out their demographic information (such as gender, age, education level and occupation), individual status and their views related to the COVID-19 pandemic. For most items, respondents only needed to answer yes or no, or answer questions using a 5-point Likert scale from 1 (not at all) to 5 (extremely). Data were collected through a professional online questionnaire platform.

In less than 2 days, 2399 participants aged 15-90 years who answered the questions completely in less than $5 \mathrm{~min}$ were included. The average age was 33.07 (12.77), among which 1413 (58.9\%) were females. Thirty-nine (1.63\%) participants lived in Hubei which was the hardest hit province during COVID-19 pandemic in China. Five hundred and eighty-nine respondents were involved in efforts to combat the pandemic, $42.95 \%$ of them were mainly engaged in healthcare security and $37.55 \%$ of them participated in the fight against COVID-19 as a volunteer (see online supplemental file 2 for more details).

The survey showed that $17.92 \%$ of the respondents held the view that there would be no second large-scale outbreak of COVID-19, while $55.98 \%$ believed that the possibility of a second outbreak was slight. This demonstrated that the vast majority of the participants held an optimistic attitude towards the pandemic, and reflected the effectiveness of China's current prevention and control measures. Meanwhile, $66 \%$ considered it is necessary to adhere to the existing standard public health measures based on mass vaccination if COVID-19 did have a large second outbreak. $45.18 \%$ of the respondents still regularly followed news reports about the pandemic (above moderate). In places or occasions where masks were not required, $48.60 \%$ of people insisted on wearing a mask. This ongoing concern seemed to suggest that many 
people were cautious about a second wave of COVID- $19^{9}$ (see online supplemental file 3 for more details).

More than $90 \%$ of the respondents chose 'largely' or 'entirely' in the question about the confidence in Chinese government's ability to deal with the subsequent outbreak (see online supplemental file 3 for more details). This is basically consistent with the level of public confidence in the government's coping ability during the rapid rise period $(97.1 \%) .{ }^{10}$ The public's strong confidence in the government could be related to the interventions implemented in China which successfully mitigated the spread and reduced overall transmission. ${ }^{11}{ }^{12}$ Moreover, the efforts of the Chinese public along with support from the international community during the rise of COVID-19 further increased public confidence.

By contrast, only $54.15 \%$ of the participants exhibited 'large' or 'entire' confidence in their ability to confront the economic, work and life stresses that would be caused by a second large-scale outbreak (see online supplemental file 3 for more details). It can be seen intuitively from this question that participants have more confidence in the government's ability to respond to the outbreak vs consequences from a second outbreak (the mean value is around 4.50 vs the mean value is around $3.50)$. First of all, it is possible that the power of the individuals is relatively small in the face of such a pandemic, so the strength of the community and assistance from the outside are particularly important at this time. During the most serious period of the pandemic in Wuhan, thousands of medical workers were dispatched and numerous medical resources were provided by other provinces. Second, individuals need to consider numerous factors, such as physical health, financial capacity and work conditions. The prevention and control policies for the pandemic can hinder the normal work, which may lead to a decrease in income and weaken the individual's coping ability.

Stress during the initial COVID-19 outbreak came from three main areas: work $(46.68 \%)$, social interaction $(37.97 \%)$ and economy (33.39\%). Meanwhile, people who perceived increased economic pressure obviously lacked confidence in the government $(\mathrm{p}<0.05)$ and individuals $(p<0.05)$. The reason for this may be that perceptions of economic stress affect individuals' attitudes (especially diminishing generalised trust) and behaviours. ${ }^{13}$ Interestingly, people of different age groups, educational levels and occupations had different views on the possibility of a second outbreak in China. Similarly, there was variability in their confidence in the government's ability to respond to the possible outbreak (figure 1). The reasons for the discrepancies need to be explored in depth with a large number of detailed studies. Additionally, participants with low educational level and less stable occupations had lower confidence in themselves. People with low educational level usually work in less stable jobs, and may face more uncertainties in their work and life. A previous study had also shown that people with a lower educational level experienced more distress during the pandemic. ${ }^{14}$
Males had more confidence in their ability to cope with a possible second wave than females $(\mathrm{p}=0.018)$. Participants who took part in efforts to combat the pandemic had more confidence in their ability to deal with the stress caused by a possible second wave $(p<0.001)$. Those who took part in efforts to fight COVID-19 may have a better understanding of protective measures and information related to the virus. This higher level of knowledge may be associated with higher confidence. ${ }^{1516}$ Furthermore, they had accumulated lots of experience in fighting against the virus during the previous wave, which also gave them more confidence.

The public had many psychological issues during the previous outbreak, such as anxiety, depression, stress and insomnia. ${ }^{17}$ When we conducted this investigation, most of them were not as anxious, nervous, worried, scared or fearful as they were during the period of rapid outbreak. If there is a confirmed case in the city where they live, $58.15 \%$ of them will not feel anxious, nervous, worried or fearful. Wearing masks, strictly preventing and controlling inbound cases and vaccination were considered to be the most effectual measures to fight against COVID-19.

Our purpose for this survey was to gauge the public's attitude towards a possible second wave of COVID-19 in China using a relatively well controlled questionnaire. Although there were slight differences among participants of different ages, educational backgrounds and occupations, they generally held an optimistic attitude towards a possible second wave of COVID-19 in China. Not only that, most of the participants had high confidence in the Chinese government and their capacity to deal with another outbreak. Even if a second outbreak does not occur, we should continue to take preventive measures. The recent situation reminds us not to relax our vigilance against the pandemic. Hopefully, this virus can be defeated in the near future.

Contributors XZ contributed to the writing and statistical analysis of this article. CJ led the whole study, including putting forward and carrying out the study, and was the corresponding author. JL contributed to revision of this article. WW contributed to performing the questionnaire and data collection. All authors read and approved the final version of the manuscript.

Funding This research was funded by the National Natural Science Foundation of China (31871171).

Competing interests None declared.

Patient consent for publication Not applicable.

Provenance and peer review Not commissioned; externally peer reviewed.

Supplemental material This content has been supplied by the author(s). It has not been vetted by BMJ Publishing Group Limited (BMJ) and may not have been peer-reviewed. Any opinions or recommendations discussed are solely those of the author(s) and are not endorsed by BMJ. BMJ disclaims all liability and responsibility arising from any reliance placed on the content. Where the content includes any translated material, BMJ does not warrant the accuracy and reliability of the translations (including but not limited to local regulations, clinical guidelines, terminology, drug names and drug dosages), and is not responsible for any error and/or omissions arising from translation and adaptation or otherwise.

Open access This is an open access article distributed in accordance with the Creative Commons Attribution Non Commercial (CC BY-NC 4.0) license, which permits others to distribute, remix, adapt, build upon this work non-commercially, 
and license their derivative works on different terms, provided the original work is properly cited, appropriate credit is given, any changes made indicated, and the use is non-commercial. See: http://creativecommons.org/licenses/by-nc/4.0/.

\section{REFERENCES}

1 World Health Organization. Current novel coronavirus (2019-nCoV) outbreak, 2020. Available: https://www.who.int/health-topics/ coronavirus [Accessed 30 Jan 2020].

2 World Health Organization. WHO Director-General's opening remarks at the media briefing on COVID19, 2020. Available: https://www.who. int/dg/speeches/detail [Accessed 11 Mar 2020].

3 Peng D, Wang Z, Xu Y. Challenges and opportunities in mental health services during the COVID-19 pandemic. Gen Psychiatr 2020;33:e100275.

4 Zhu N, Zhang D, Wang W, et al. A novel coronavirus from patients with pneumonia in China, 2019. N Engl J Med 2020;382:727-33.

5 Nelson BW, Pettitt A, Flannery JE, et al. Rapid assessment of psychological and epidemiological correlates of COVID-19 concern, financial strain, and health-related behavior change in a large online sample. PLoS One 2020;15:e0241990.

6 Ngwewondo A, Nkengazong L, Ambe LA, et al. Knowledge, attitudes, practices of/towards COVID 19 preventive measures and symptoms: a cross-sectional study during the exponential rise of the outbreak in Cameroon. PLoS Negl Trop Dis 2020;14:e0008700.

7 Li Z-H, Zhang X-R, Zhong W-F, et al. Knowledge, attitudes, and practices related to coronavirus disease 2019 during the outbreak among workers in China: a large cross-sectional study. PLoS Negl Trop Dis 2020;14:e0008584.
8 Hezima A, Aljafari A, Aljafari A, et al. Knowledge, attitudes, and practices of Sudanese residents towards COVID-19. East Mediterr Health J 2020;26:646-51.

9 Xu S, Li Y. Beware of the second wave of COVID-19. Lancet 2020;395:1321-2.

10 Zhong B-L, Luo W, Li H-M, et al. Knowledge, attitudes, and practices towards COVID-19 among Chinese residents during the rapid rise period of the COVID-19 outbreak: a quick online cross-sectional survey. Int J Biol Sci 2020;16:1745-52.

11 Kraemer MUG, Yang C-H, Gutierrez B, et al. The effect of human mobility and control measures on the COVID-19 epidemic in China. Science 2020;368:493-7.

12 Leung K, Wu JT, Liu D, et al. First-wave COVID-19 transmissibility and severity in China outside Hubei after control measures, and second-wave scenario planning: a modelling impact assessment. Lancet 2020;395:1382-93.

13 Navarro-Carrillo G, Valor-Segura I, Lozano LM, et al. Do economic crises always undermine trust in others? the case of generalized, interpersonal, and In-Group trust. Front Psychol 2018;9:9.

14 Zhou Q, Hu Z, Bian G, et al. Mental health and psychosocial function of general population during the COVID-19 epidemic in China. Clin Transl Med 2020;10:e103.

15 Iqbal MA, Younas MZ. Public knowledge, attitudes, and practices towards COVID-19 in Pakistan: a cross-sectional study. Child Youth Serv Rev 2021;120:105784.

16 Baseer M-A, Ansari S-H, AIShamrani S-S, et al. Awareness of droplet and airborne isolation precautions among dental health professionals during the outbreak of corona virus infection in Riyadh City, Saudi Arabia. J Clin Exp Dent 2016;8:e379-87.

17 Peretti-Watel P, Alleaume C, Léger D, et al. Anxiety, depression and sleep problems: a second wave of COVID-19. Gen Psychiatr 2020;33:e100299.

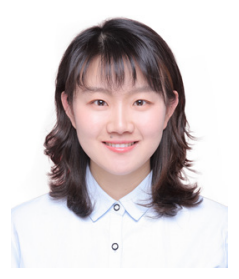

Xiaona Zhou obtained a master's degree in psychology from Dalian Medical University in Dalian, China, in 2016. Since January 2019, she has been working as a teaching assistant at the Faculty of Psychology, Naval Medical University (Second Military Medical University) in Shanghai, China. Prior to this, she served as a psychological counselor and primary psychotherapist at Qingdao special serviceman recuperation center of navy. Her main research interests include mental health care and stress protection. 